\title{
Knodell Fibrosis Score
}

National Cancer Institute

\section{Source}

National Cancer Institute. Knodell Fibrosis Score. NCI Thesaurus. Code C119571.

A scoring system for liver fibrosis developed by Knodell et al (Knodell RG, Ishak KG, Black

WC, et al. Formulation and application of a numerical scoring system for assessing

histological activity in asymptomatic chronic active hepatitis. Hepatology 1981;1:431),

based on a 4 category scale. 